\title{
Oral Appliance Therapy Should be Reimbursed After CPAP Intolerance
}

\author{
Rosemarie Rohatgi, DMD, D.ABDSM${ }^{1}$, Kenneth Mogell, DMD, D.ABDSM², David B. Schwartz, DDS, D.ABDSM ${ }^{3}$ \\ ${ }^{1}$ San Diego Sleep Therapy, ${ }^{2}$ Florida Dental Sleep Disorders, ${ }^{3}$ Sleep Better Chicagoland
}

\section{INTRODUCTION}

It is the position of the American Academy of Dental Sleep Medicine (AADSM) that payers should cover oral appliance therapy (OAT) provided by a qualified dentist after a physician has determined that the patient is intolerant to Continuous Positive Airway Pressure (CPAP).

Current scholarly data indicate that OAT successfully manages OSA ${ }^{1,2}$ and is cost effective. ${ }^{3,4}$ The AADSM convened a task force of experts with the goal to review evidence in favor of OAT reimbursement. Thus, this paper will explore the evidence in favor of OAT reimbursement.

\section{WHAT IS CPAP INTOLERANCE?}

Before exploring OAT, it is important to understand CPAP intolerance. Although no standard definition of CPAP intolerance exists, the two most common reasons for patient discontinuation of CPAP therapy are side effects affecting the nose or pharynx and the patient's lack of perceived benefit. ${ }^{5}$ Other reasons may include mask-induced feelings of claustrophobia, disturbance from noise, and mask leakage. ${ }^{5}$

Related to tolerance, The Centers for Medicare and Medicaid Services (CMS) define CPAP adherence as use of CPAP for " 4 or more hours per night on $70 \%$ of nights during a consecutive 30-day period anytime during the first 3 months of initial use". ${ }^{6}$ CMS has argued that 12 weeks ( 3 months) is sufficient time to determine CPAP adherence and tolerance. ${ }^{7}$

\section{OAT EFFECTIVELY TREATS OSA}

\section{Reduction in Apnea-Hypopnea Index and Respiratory Disturbance Index}

When a patient cannot tolerate CPAP, empirical evidence indicates that OAT can be highly effective in reducing the severity of major OSA symptoms. Numerous studies have shown that use of oral appliances (OAs), and in particular, a custom-fit Mandibular
Advancement Device (MAD), can lead to a reduction in apnea-hypopnea index among patients with OSA. ${ }^{1}$ Additionally, OAT has been associated with decreased respiratory disturbance index (RDI) in those with OSA. In one randomized controlled trial, RDI was significantly lower among patients with a Mandibular Advancement Splint (MAS) compared to patients who received no treatment. ${ }^{2}$ These studies support the use of OAT in favor of no treatment.

\section{Improvement in Short-Term Side Effects of OSA}

Empirical evidence has shown that OAT can improve short-term side effects of OSA, including high blood pressure, disturbed sleep, and reduced quality of life.

Reduced Blood Pressure: Sleep-related breathing disorders (SRBD) have been associated with cardiovascular disease, such as hypertension. ${ }^{8}$ Studies have shown promising results for OAT in reducing blood pressure (BP) among patients with OSA. In a randomized, controlled trial of OAT on patients with OSA, those in the treatment group experienced significant reduction in 24-hour diastolic BP compared to the control group, over the course of 4 weeks. ${ }^{9}$ Another randomized trial found that $\mathrm{OAT}$ was associated with significant reduction of nocturnal BP among women with OSA, although these findings were not the same for men, indicating sex differences in BP response to OAT. ${ }^{10}$ Overall, evidence has shown that OA may be similar to CPAP in effect on BP. ${ }^{9,11}$

Improved Sleep Quality: OAT has been associated with improvements in self-reported sleepiness when compared with no treatment ${ }^{12,13}$ and has a similar effect on self-reported sleepiness when compared to CPAP. ${ }^{14}$ OAT has also been associated with improvements in subjective sleep quality and daytime sleepiness. ${ }^{15}$

OSA-related drowsiness has been linked with higher risk of motor vehicle and workplace accidents. ${ }^{16,17}$ Such accidents have been estimated to cost the U.S. economy roughly $\$ 33$ billion annually. ${ }^{17}$

OAT may aid in reducing such costs. In one randomized controlled trial to compare MAD therapy to 
CPAP, MAD therapy improved patient-simulated driving equally to CPAP. This may indicate that MAD therapy can reduce the risk of OSA-related crashes. ${ }^{18}$

Improved Quality of Life: Evidence shows that OAT can improve the quality of life for those with mild to moderate sleep apnea, when compared with no treatment. ${ }^{19}$ OAT has been associated with improvements in fatigue and energy levels, as well as reduction in symptoms of depression. ${ }^{12}$

\section{Improvement in Long-Term Side Effects of OSA}

OSA has been linked to a number of long-term comorbidities including diabetes, heart failure, ${ }^{20}$ and potentially, Alzheimer disease. ${ }^{21}$ OAT may potentially reduce risk of such diseases. One observational study indicated that those who were treated with MAD were at less risk of a fatal cardiovascular event (e.g. sudden cardiac arrest, stroke, myocardial infarction) than those who were not treated..$^{22}$ In fact, OAT may be as effective as CPAP therapy in reducing the chance of "fatal cardiovascular events in patients with severe OSA."22

\section{OAT IS COST EFFECTIVE}

Considering the high costs of cardiovascular disease, accidents, and other side effects of OSA, in situations where a patient is unable or unwilling to tolerate CPAP, use of OAT is far more cost effective than leaving OSA untreated..$^{3,4}$ Furthermore, economic analyses have indicated that as CPAP compliance diminishes, the cost effectiveness of OAT increases. ${ }^{3}$ When considering lower CPAP compliance, in mild cases of OSA, OAT may be even more cost effective than CPAP. $^{3}$

Overall, studies have indicated that patient adherence to CPAP is low. ${ }^{23}$ Conversely, objective measurement of OAT compliance has indicated that adherence is quite high. In one study using objective measurement of adherence, $93 \%$ of patients in the study were considered compliant with treatment ( $>4$ hours of use per night). ${ }^{24}$ Although CPAP is generally considered to have greater efficacy in improving symptoms of OSA, higher compliance rates may increase the relative effectiveness of OAT when compared to CPAP. ${ }^{25,26}$ Data on adherence and cost effectiveness indicate that it is highly economically advantageous to reimburse OAT after CPAP has failed.

\section{CONCLUSION}

Empirical evidence supports the use of OAT to effectively treat OSA. OAT has demonstrated positive effect on health and quality-of-life outcomes. Furthermore, when considering patient compliance rates, OAT may be as effective as CPAP and is certainly far more cost effective than leaving OSA untreated.

It is the position of the AADSM that all OAT should be delivered by a qualified dentist, as OAT requires the skills, knowledge, and judgment to appropriately treat OSA, recognize improved health outcomes, and manage side effects. ${ }^{27}$ However, when delivered appropriately, OAT is far superior to no treatment for patients with OSA. Thus, payers should consider reimbursing OAT when a patient is unable or unwilling to tolerate CPAP therapy.

\section{CITATION}

Rohatgi R, Mogell K, Schwartz DB. Oral appliance therapy should be reimbursed after CPAP intolerance. J Dent Sleep Med. 2019;6(1)

\section{REFERENCES}

1. Andrén A, Hedberg $P$, Walker-Engström M-L, Wahlén $P$, Tegelberg A. Effects of treatment with oral appliance on 24-h blood pressure in patients with obstructive sleep apnea and hypertension: a randomized clinical trial. Sleep Breath. 2013;17(2):705-712. doi:10.1007/s11325-012-0746-7

2. Gotsopoulos H, Chen C, Qian J, Cistulli PA. Oral appliance therapy improves symptoms in obstructive sleep apnea: a randomized, controlled trial. Am J Respir Crit Care Med. 2002;166(5):743-748. doi:10.1164/rccm.200203-208OC

3. Sharples L, Glover M, Clutterbuck-James A, et al. Clinical effectiveness and cost-effectiveness results from the randomised controlled Trial of Oral Mandibular Advancement Devices for Obstructive sleep apnoea-hypopnoea (TOMADO) and long-term economic analysis of oral devices and continuous positive airwa. Health Technol Assess (Rockv). 2014;18(67):1-296. doi:10.3310/hta18670

4. Sadatsafavi M, Marra CA, Ayas NT, Stradling J, Fleetham J. Costeffectiveness of oral appliances in the treatment of obstructive sleep apnoea - Hypopnoea. Sleep Breath. 2009;13(3):241-252. doi:10.1007/s11325-009-0248-4

5. Janson C, Nöges E, Svedberg-Brandt S, Lindberg E. What characterizes patients who are unable to tolerate continuous positive airway pressure (CPAP) treatment? Respir Med. 2000;94(2):145-149. doi:10.1053/rmed.1999.0703

6. Department of Health and Human Services, Centers for Medicare \& Medicaid Services. Positive Airway Pressure (PAP) Devices: Complying with Documentation \&amp; Coverage Requirements.; 2016. https://www.cms.gov/Outreach-and-Education/MedicareLearning-Network-

MLN/MLNProducts/downloads/PAP_DocCvg_FactSheet_ICN90 5064.pdf. Accessed August 6, 2018.

7. Jacques L, Spencer F. Decision Memo for Continuous Positive Airway Pressure ( CPAP) Therapy for Obstructive Sleep Apnea ( OSA ) ( CAG-00093R2 ). 2009;32:1-35 https://www.cms.gov/medicare-coverage-database/details/ncadecision-memo.aspx?NCAId=204. Accessed July 18, 2018.

8. Nieto FJ, Young TB, Lind BK, et al. Association of sleepdisordered breathing, sleep apnea, and hypertension in a large community-based study. Sleep Heart Health Study. JAMA. 2000;283(14):1829. doi:10.1001/jama.283.14.1829

9. Gotsopoulos H, Kelly JJ, Cistulli PA. Oral appliance therapy reduces blood pressure in obstructive sleep apnea: a randomized, $\begin{array}{llll}\text { controlled trial. } & \text { Sleep. } & \text { 2004;27(5):934-941. }\end{array}$ doi:10.1093/sleep/27.5.934

10. Rietz H, Franklin KA, Carlberg B, Sahlin C, Marklund M. Nocturnal blood pressure is reduced by a mandibular advancement 
device for sleep apnea in women: findings from secondary analyses of a randomized trial. $J$ Am Heart Assoc. 2018;7(13):e008642. doi:10.1161/JAHA.118.008642

11. Otsuka R, Ribeiro De Almeida F, Lowe AA, Linden W, Ryan F. The effect of oral appliance therapy on blood pressure in patients with obstructive sleep apnea. Sleep Breath. 2006;10:29-36. doi:10.1007/s11325-005-0038-6

12. Naismith SL, Winter VR, Hickie IB, Cistulli PA. Effect of oral appliance therapy on neurobehavioral functioning in obstructive sleep apnea: a randomized controlled trial. J Clin Sleep Med. 2005;1(4):374-380. http://jcsm.aasm.org/Articles/010409.pdf. Accessed July 11, 2018.

13. Petri N, Svanholt P, Solow B, Wildschiødtz G, Winkel P. Mandibular advancement appliance for obstructive sleep apnoea: Results of a randomised placebo controlled trial using parallel group design. $J$ Sleep Res. 2008;17(2):221-229. doi:10.1111/j.1365-2869.2008.00645.x

14. Barnes M, McEvoy RD, Banks S, et al. Efficacy of positive airway pressure and oral appliance in mild to moderate obstructive sleep apnea. Am J Respir Crit Care Med. 2004;170(6):656-664. doi:10.1164/rcem.200311-15710C

15. Mehta A, Qian J, Petocz P, Darendeliler MA, Cistulli PA. A randomized, controlled study of a mandibular advancement splint for obstructive sleep apnea. Am J Respir Crit Care Med. 2001;163(6):1457-1461. doi:10.1164/ajrccm.163.6.2004213

16. Tregear S, Reston J, Schoelles K, Phillips B. Obstructive sleep apnea and risk of motor vehicle crash: Systematic review and metaanalysis. J Clin Sleep Med. 2009;5(6):573-581.

17. Frost \& Sullivan. Hidden Health Crisis Costing America Billions: Underdiagnosing and Undertreating Obstructive Sleep Apnea Draining Healthcare System. Darien, Am Acad Sleep Med 2016. 2016. https://aasm.org/resources/pdf/sleep-apnea-economiccrisis.pdf. Accessed July 19, 2018.

18. Phillips CL, Grunstein RR, Darendeliler MA, et al. Health outcomes of continuous positive airway pressure versus oral appliance treatment for obstructive sleep apnea. Am J Respir Crit Care Med. 2013;187(8):879-887. doi:10.1164/rccm.201212$2223 \mathrm{OC}$

19. Marklund M, Verbraecken J, Randerath W. Non-CPAP therapies in obstructive sleep apnoea: Mandibular advancement device therapy. Eur Respir J. 2012;39(5):1241-1247. doi:10.1183/09031936.00144711

20. Gottlieb DJ, Yenokyan G, Newman AB, et al. Prospective study of obstructive sleep apnea and incident coronary heart disease and heart failure: The sleep heart health study. Circulation. 2010;122(4):352-360.

doi:10.1161/CIRCULATIONAHA.109.901801

21. Liguori C, Mercuri NB, Izzi F, et al. Obstructive sleep apnea is associated with early but possibly modifiable Alzheimer's disease biomarkers changes. Sleep. 2017;40(5). doi:10.1093/sleep/zsx011

22. Anandam A, Patil M, Akinnusi M, Jaoude P, El-Solh AA. Cardiovascular mortality in obstructive sleep apnoea treated with continuous positive airway pressure or oral appliance: An observational study. Respirology. 2013;18(8):1184-1190. doi: $10.1111 /$ resp. 12140

23. Mckay Wallace D, Schwartz SJ, Wallace DM, et al. Determinants of continuous positive airway pressure adherence in a sleep clinic cohort of South Florida Hispanic veterans. Sleep Breath. 2012;17(1):351-363. doi:10.1007/s11325-012-0702

24. Vanderveken OM, Dieltjens M, Wouters K, De Backer WA, Van De Heyning PH, Braem MJ. Objective measurement of compliance during oral appliance therapy for sleep-disordered breathing. Thorax. 2013;68(1):91-96. doi:10.1136/thoraxjn1-2012-201900

25. Sutherland K, Phillips CL, Cistulli PA. Efficacy versus effectiveness in the treatment of obstructive sleep apnea: CPAP and oral appliances. J Dent Sleep Med. 2015;2(4):175-181. doi: $10.15331 / \mathrm{jdsm} .5120$

26. Sutherland K, Vanderveken OM, Tsuda H, et al. Oral Appliance Treatment for Obstructive Sleep Apnea: An Update. J Clin Sleep Med. 2014;10(2):215-227. doi:10.5664/jcsm.3460

27. Ramar K, Dort LC, Katz SG, et al. Clinical Practice Guideline for the Treatment of Obstructive Sleep Apnea and Snoring with Oral Appliance Therapy: An Update for 2015. J Clin Sleep Med. 2015; 11(7):773-827. doi: 10.5664/jcsm.4858

\section{SUBMISSION AND CORRESPONDENCE INFORMATION}

\section{Submitted in final revised form August 23, 2018 Accepted for publication August 23, 2018}

Address correspondence to: Rosemarie Rohatgi, DMD, D.ABDSM, San Diego Sleep Therapy, 5414 Oberlin Drive, Suite 235 San Diego, California 92121

\section{DISCLOSURE STATEMENT}

Dr. Rohatgi reports accepting speaker's fees for an American Sleep and Breathing Academy conference and serving as part of an advisory group for Prosomnus. Dr. Schwartz reports serving as part of an advisory group for Prosomnus and having a financial stake in Prosomnus. The other author reports no conflicts of interest. 